\title{
Original Clinical Research
}

\section{Psychological and behavioral changes in cancer patients and their attitude towards the stressful condition and physiological changes}

Priyanka Yadav, D P Jaroli

\begin{abstract}
Objectives : To evaluate the psychological and behavioral changes in cancer patients and their attitude to wards the stressful condition and physiological changes .

Study design : Tertiary hospital based prospective cross sectional analysis .

Setting: Cancer patients visited at tertiary level hospital for their treatment and follow up .

Study subjects: All age group cancer patients.

Main outcome measures: Patients'attitude about cancer and coping measures for stressful condition be fore, after and during treatment.

Results: A very broad spectrum of problems that faced by patient contains physical and psychological complaints, social problems etc. As can be seen, the most frequent problems were generalized weakness (20.95\%), the fear of disease progression (30.17\%) and feeling of tense and nervousness $(24.86 \%)$. Overall changes in impaired physical activities (34.36\%) and mental status (22.35\%) were observed by patients before and after treatment. The findings of present survey it has been observed that the patients involved in cancer undergo several physical and psychological effects .

Conclusions : This research survey suggests that support from the physician ; family members and society people play a very important role to encourage the patients to fight against the disease . Such kind of awareness is of great significance for decreasing the morbidity rate and better quality of life of patients .
\end{abstract}

Key words : Cancer ; Psychological factor ; Chemotherapy ; Anxiety ; India

Received: June 16,2011

Accepted:August 7,2011

doi : $10.5430 /$ jst. v1n1 p15

\section{INTRODUCTION}

Cancer is not just a single stressful situation. It is a complex and variable stressor in different stages of the disease and different environmental setting. Evidence suggests that pre existing psychological fac tors. Patients bring to their cancer experience could

Department of Zoology, University of Rajasthan, Jaipur, Rajasthan, India.

Corresponding author : Priyanka Yadav, Department of Zoology, University of Rajasthan, Jaipur, Rajasthan, India; Tel : +91-9660062552 ;E-mail: priyanyadav@yahoo.co.in. significantly affect their adaptation to cancer. In addition studies have shown that 3 points of increased distress for cancer. Patients are at diagnosis, at recurrence or progression of the disease and at the ter minal stage ${ }^{1}$.

Stress disorder had been studied in wide range of cancers. The incidence of stress syndrome ranged from $3 \%$ to $4 \%$ in patients recently diagnosed with early-stage cancer to $35 \%$ in patients after treatment. Posttraumatic symptoms were much more common, ranging in frequency from $20 \%$ in patients with 
early-stage cancer to $80 \%$ in those with a recent recurrence of cancer. Symptom incidence and severity was affected by many factors, including the type and stage of cancer, treatment severity, prior trauma, current and past social support, and the personality and coping style of the affected individuals ${ }^{2}$.

Results indicated that $47 \%$ of the patients received a DSM -III diagnosis, with $44 \%$ being diagnosed as manifesting a clinical syndrome and 3\% with personality disorders. Approximately 68\% of the psychiatric diagnoses consisted of adjustment dis orders, with $13 \%$ representing major affective disorders (depression). The remaining diagnoses were split among organic mental disorders $(8 \%)$, personality disorders (7\%), and anxiety disorders (4\%). Approximately $85 \%$ of those patients with a positive psychiatric condition were experiencing a disorder with depression or anxiety as the central symptom. The large majority of conditions were judged to represent highly treatable disorders ${ }^{3}$.

The authors measured the rate and determinants of posttraumatic stress disorder (PTSD) in a group of cancer survivors. Patients who had a history of cancer diagnosis with at least 3 years since diagnosis, receiving no active treatment, such as chemotherapy or radiation, were interviewed $(n=27)$. Patients, who were part of the DSM -IV PTSD field trial, were compared with a community - based control group matched for age and socioeconomic status. One member of the survivor group (4\%) and no members of the control group met criteria for current PTSD (NS). Six of the survivors (22\%) and no control subjects met lifetime criteria $(P<0.02)$. Cancer patients have a higher rate of PTSD than found in the community. Symptoms closely resemble those of indi viduals who have experienced other traumatic events $^{4}$.

Breast cancer survivors most frequently report ex periencing emotional distress (e. g. , depression and anxiety symptoms) and intrusion and avoidance (e. g. , intrusive thoughts, feelings, and imagery ; numbing of responsiveness and avoidance of feelings , situations, or ideas) in relation to cancer and its treat- ment. Cancer and its treatment may provoke severe physical and psychological complaints. Breast cancer seems to be more stressful because this disease and its medical treatment can afflict the sense of feminini ty, perceived sexuality, and fertility of its victims ${ }^{5}$.

This study is carried out to determine the impact of diagnosis and treatment of cancer on patient and their attitude with coping measures for stressful condition before, after and during treatment.

\section{MATERIALS AND METHOD}

The study survey was done in the tertiary level cancer center in Rajasthan. The survey sample comprised 358 cancer patients of all aged group. All patients were required to give consent prior to participating for this survey. Patients were also informed of the nature of the survey and were told they can participate or leave the survey anytime. This study was done from April 2010 to December 2010.

Study Design : A tertiary hospital based prospective cross sectional analysis.

Participants : All age group cancer patients visited at tertiary level hospital for their treatment and follow up.

Sample size: All cancer patients visited to cancer center were eligible to take part in the study.

\section{Procedure}

All patients were required to give consent prior to participating and patients were also informed of the nature of the study survey. The patients were interviewed after explaining them the purpose of study and to encourage responses from them, the subjects were interviewed after establishing rapport and assur ing them of confidentiality. All the questionnaires were completed by daily visiting the cancer center. Base line demographic information was obtained on age, initial diagnosis, length of time since diagnosis and effects of treatment on physical and mental health. For collecting information instrument so used was questionnaire was designed after with help of questionnaire on Stress in Cancer Patients ( QSC $\mathrm{R} 23)^{6}$. It was modified with necessary changes so 
felt after discussing with experts of this field. Patient was asked to complete a questionnaire with 36 questions.

\section{Statistical Analysis}

Data was collected, complied and analyzed. The data collected on all parameters was organized in tabulated form for further analysis. Also statistical comparisons were examined for major variables in the study. It was analyzed using Biostatistics formulas.

\section{RESULTS}

The total patients demographic and disease related details are comprises in Table 1. All patients are between 8 to 65 years old. For this survey we divided parameters like age, gender, marital status, metastatic, duration of diagnosis and treatment phase in two categories. In order to find out which medical and demographic factors have an impact on the dis tress of the patients, mean total stress score was measured and corresponding subgroup comparisons was done in Table 2. The result of this analysis showed that stress score is higher comparative to other group in older age married male patients who had metastasis and those have in follow up phase be cause of fear of disease progression.

There were 7 different diagnostic subgroups as per indication. The most frequent were lung cancer $(21.23 \%)$, breast $(18.72 \%)$, head/neck (18.72\%), hematological cancers ( $13.97 \%)$, genitourinary and gastrointestinal cancers ( $12.57 \%$ $\& 10.61 \%$ ) respectively. A total of 15 patients had cancers of unknown primary tumor or very uncommon cases. In all cases, $67.32 \%$ cases were on treatment phase and taking chemotherapy/radiotherapy while $32.68 \%$ cases in follow up period.

The mean scores for the three subscales were : Impaired Physical functions Mean $=2.05(\mathrm{SD}=$ 0.79 ), psychological/behavioral complaints $\mathrm{M}=$ 2. $37(\mathrm{SD}=0.97)$ and family \& social strains Mean $=2.37(\mathrm{SD}=1.03)$. The total score is $\mathrm{M}=2.26$ $(\mathrm{SD}=0.93)$.
Table 1 Demographic and disease description

\begin{tabular}{|c|c|c|}
\hline & $\mathrm{n}$ & $\%$ \\
\hline \multicolumn{3}{|l|}{ Age } \\
\hline$<40$ year & 94 & $26.26 \%$ \\
\hline$\geqslant 40$ year & 264 & $73.74 \%$ \\
\hline \multicolumn{3}{|l|}{ Gender } \\
\hline Male & 261 & $72.91 \%$ \\
\hline Female & 97 & $27.09 \%$ \\
\hline \multicolumn{3}{|l|}{ Marital Status } \\
\hline Married & 307 & $85.75 \%$ \\
\hline Unmarried & 51 & $14.25 \%$ \\
\hline \multicolumn{3}{|l|}{ Cancer diagnosis } \\
\hline Breast & 67 & $18.72 \%$ \\
\hline Respiratory tract & 76 & $21.23 \%$ \\
\hline Genitourinary tract & 45 & $12.57 \%$ \\
\hline Hematological & 50 & $13.97 \%$ \\
\hline Head \& Neck cancer & 67 & $18.72 \%$ \\
\hline Gastrointestinal & 38 & $10.61 \%$ \\
\hline Others & 15 & 4. $19 \%$ \\
\hline \multicolumn{3}{|l|}{ Metastasis } \\
\hline Yes & 110 & $30.73 \%$ \\
\hline No & 248 & $69.27 \%$ \\
\hline \multicolumn{3}{|l|}{ Duration of disease } \\
\hline$<6$ month & 122 & $34.08 \%$ \\
\hline$\geqslant 6$ month & 236 & $65.92 \%$ \\
\hline \multicolumn{3}{|l|}{ Therapeutic status } \\
\hline Treatment Phase & 241 & $67.32 \%$ \\
\hline Follow up Phase & 117 & $32.68 \%$ \\
\hline
\end{tabular}

Table 2 Mean total stress score and corresponding subgroup comparisons

\begin{tabular}{|c|c|c|}
\hline & mean & S. D. \\
\hline \multicolumn{3}{|l|}{ Age } \\
\hline$<40$ year & 1.54 & 0.84 \\
\hline$\geqslant 40$ year & 1.69 & 0.95 \\
\hline \multicolumn{3}{|l|}{ Gender } \\
\hline Male & 1.66 & 0.93 \\
\hline Female & 1.60 & 0.90 \\
\hline \multicolumn{3}{|l|}{ Marital Status } \\
\hline Married & 1.95 & 0.94 \\
\hline Unmarried & 1.32 & 0.83 \\
\hline \multicolumn{3}{|l|}{ Metastasis } \\
\hline Yes & 1.70 & 0.91 \\
\hline No & 1.56 & 0.94 \\
\hline \multicolumn{3}{|l|}{ Duration of disease } \\
\hline$<6$ month & 1.49 & 0.91 \\
\hline$\geqslant 6$ month & 1.77 & 0.92 \\
\hline \multicolumn{3}{|l|}{ Therapeutic status } \\
\hline Treatment Phase & 1.53 & 0.92 \\
\hline Follow up Phase & 1.73 & 0.93 \\
\hline
\end{tabular}


Table 3 Specific questionnaire and ranked mean stress scores

\begin{tabular}{|c|c|c|c|}
\hline Questionnaire & Mean & SD & $\%$ of High Score \\
\hline Sleeping habits have changed & 1.70 & 0.75 & $1.68 \%$ \\
\hline Experienced a change in my appetite & 1.92 & 0.81 & $3.91 \%$ \\
\hline Pain and discomfort have limited daily activities & 1.69 & 0.69 & $1.68 \%$ \\
\hline Cancer and its treatment have caused changes in physical appearance & 1.23 & 0.57 & $1.96 \%$ \\
\hline Feeling tired and weak & 2.77 & 0.97 & $20.95 \%$ \\
\hline Overall feeling of physically imperfect & 2.65 & 0.76 & $14.80 \%$ \\
\hline Cancer treatment side effects have more problem then cancer itself & 2.37 & 0.98 & $14.80 \%$ \\
\hline Feel irritable or unusually angry and not controlled it well & 2. 20 & 0.86 & $6.98 \%$ \\
\hline Difficulty on concentrating at work or at home or daily routine things & 2. 11 & 0.83 & $3.63 \%$ \\
\hline Difficulty coping with the stress that have experienced & 2.15 & 1.03 & $11.45 \%$ \\
\hline Quality of life before and after treatment has been changed & 2.42 & 0.95 & $10.34 \%$ \\
\hline Being afraid of disease progression & 2.65 & 1.31 & $30.17 \%$ \\
\hline Being afraid of having to go to the hospital again & 2.47 & 0.73 & $11.45 \%$ \\
\hline Being afraid of developing pain & 2.36 & 1.01 & $13.97 \%$ \\
\hline Feeling often tense and nervous & 2.61 & 1.17 & $24.86 \%$ \\
\hline Being afraid of not being able to work anymore & 2.50 & 0.87 & $14.25 \%$ \\
\hline Can not talk about emotional problems & 2.25 & 1.12 & $13.69 \%$ \\
\hline Feeling unconfident in relationships with other people & 2.50 & 0.82 & $13.13 \%$ \\
\hline Having the feeling of being less value for other people & 2.40 & 0.82 & $8.66 \%$ \\
\hline Feeling of not well informed about illness/treatment & 2.25 & 1.09 & $14.25 \%$ \\
\hline Cancer and its treatment have interfered with family or social life & 1.94 & 0.86 & $1.68 \%$ \\
\hline Cancer and its treatment have interfered with married life & 2.18 & 1.10 & $12.01 \%$ \\
\hline Cancer has caused financial problem. & 2.40 & 1.08 & $12.85 \%$ \\
\hline Family is anxious or worried about cancer diagnosis/ treatment. & 2.27 & 1.11 & $16.20 \%$ \\
\hline Family members depressed or discouraged. & 2.58 & 0.94 & $17.88 \%$ \\
\hline Family members feel difficulty concentrating at work, home or school & 2.24 & 1.10 & $12.85 \%$ \\
\hline Difficulty coping with the stress that the entire family is experiencing. & 2.23 & 1.04 & $12.57 \%$ \\
\hline Going out less in social environment & 2. 11 & 1.10 & $11.45 \%$ \\
\hline Difficulty for partner to empathies my situation & 2.33 & 0.91 & $7.54 \%$ \\
\hline Other people react inconsiderately/unsympathetically & 2.44 & 1.18 & $20.11 \%$ \\
\hline Overall Changes in physical activities before and after treatment & 2.97 & 1.01 & $34.36 \%$ \\
\hline Overall Changes in mental status before and after treatment & 2.61 & 1.23 & $22.35 \%$ \\
\hline Overall Changes in behavior for others before and after treatment & 2.58 & 0.79 & $13.41 \%$ \\
\hline Overall Changes in behavior of other before and after treatment & 2.31 & 1.04 & $13.97 \%$ \\
\hline Your response when came to know about suffering from cancer & 3.41 & 0.56 & $44.41 \%$ \\
\hline Family reaction when came to know that you were suffering from cancer & 3.12 & 0.65 & $27.93 \%$ \\
\hline
\end{tabular}

A very broad spectrum of problems that faced by patient and family members at the time of diagnosis , during the treatment phase and in follow up phase is mapped here. It contains physical and psychological complaints, social problems etc. As can be seen, the most frequent problems were generalized weak - 
ness $(20.95 \%)$, the fear of disease progression (30. 17\%) and feeling of tense and nervousness $(24.86 \%)$. Overall changes in impaired physical activities (34.36\%) and mental status (22.35\%) were observed by patients before and after treatment .

The results are presented at the stress scores (as per questionnaire set for this survey) for the total sample. The ranked mean stress scores of the questionnaire for the total sample are presented in Table 3.

\section{Patient response at the time of diagnosis}

To record the response of the patients on the diagno sis of cancer, all patients were asked that what their reaction was when they came to know that they were suffering from cancer. Majority of patients (52.23\%) responded that they became very depressed and developed pessimistic attitude , 44. $41 \%$ patients responded that on hearing this news they be came depressed but decided to fight against the dis ease ( Figure 1).

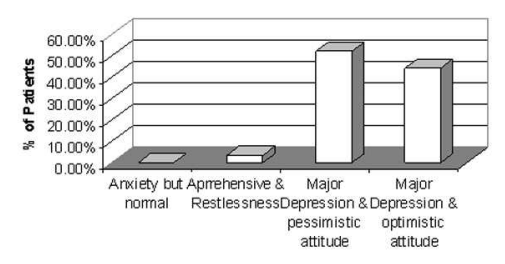

Figure 1 Patients response at the time of diagnosis

\section{Family member and caregiver response at the time of diagnosis}

The response of 358 patients who were asked that what the response of their family members was when they came to know about suffering from life threaten ing cancer. Out of $358,55.23 \%$ patients replied that on hearing this news their family members became upset and showed optimistic attitude with full cooperation and encouraged him to fight against the disease, $27.93 \%$ patients responded that their family members showed pessimistic attitude towards him ( Figure 2).

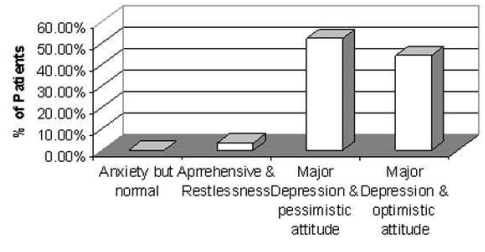

Figure 2 Family response at the time of diagnosis

\section{Patient apprehension during treatment and fol- low up}

Most of the patients were apprehensive about future recurrence and progression of disease. Because of this fear $30.17 \%$ cases were in major depression and only $8.38 \%$ patients showed optimistic attitude towards this fear.

\section{Patient mental status before and after treatment}

Most of the patients $(54.47 \%)$ were apprehensive and have some degree of depression so their daily ac tivity is hampered. Only $45.53 \%$ cases reported that they have no to little bit of anxiety.

\section{Patient Quality of life before and after treatment}

All the patients responded that their quality of life was affected once they diagnosed with this dreaded disease. This may be due to disease itself and its treatment. Only $10.34 \%$ patients told that they have worst experience of life.

\section{Patient unusual behavior towards others}

Most of the patients (78.21\%) were irritable attitude towards others after disease diagnosis and during treatment phase, this may be due to some degree of anxiety and depression. Only $21.79 \%$ cases reported that they have same attitude as previously before diagnosis.

\section{Patient physical impairment}

After the diagnosis of cancer the sleep duration of a person is usually affected. To record these information all patients were asked about their sleep after di agnosis of cancer. Out of 358, half of the 
(54. 19\%) patients replied that their sleep was disturbed and decreased and night awakening was frequent because of anxiety and some disease related pain. Pain is the troublesome complication of advanced cancer. More than half of patients (57.54\%) experience the pain and discomfort. This was the main reason to affect the daily activities. In those patients ( $17.60 \%)$ who had surgical treatment modality have faced the psychological problem and some depression because of disfiguration of body part. This problem was mostly in breast and head/ neck surgical cases.

\section{Effect of cancer treatment on daily activities}

Total $73.74 \%$ of the patients replied that they were not able to concentrate on their work and self daily activities. Severally affected patients with this problem were $3.63 \%$ cases. The side effects are the unbearable complication of cancer treatment. There were two category of patients, one group ( $34.08 \%$ ) on treatment phase responded that at present discom fort due to chemotherapy was unbearable then cancer itself. This was also supported by another group (14.80\%) in follow up phase.

\section{Financial burden effects}

Total $98.32 \%$ patients have financial problem while they were taking cancer treatment. This indirect factor may change the attitude and add some more anxi ety to the patients.

\section{Impact of disease on social life of the patient}

All human beings prefer to live in social environ ment. But after the diagnosis of cancer some patients withdraw themselves from social activities and restrict themselves to within. Only $11.45 \%$ patients responded that they are going out less in social environment after diagnosed with cancer .

\section{Overall changes in behavior of people with the patient after diagnosis}

After diagnosis of cancer behavior of the people with the patient is changed and mostly people took sympa- thy for the patient. Only $25 \%$ patients replied that the behavior of people with them after diagnosis be came same as previous and more cooperative, $13.97 \%$ patients said that the behavior of people with them was unsympathetically or rejected type.

\section{DISCUSSION}

The aims of the study research were to evaluate the psychological and behavioral changes in cancer pa tients and their attitude towards the stressful condi tion and physiological changes occurred in body .

Derogatis and colleagues ${ }^{3}$ found that $47 \%$ of patients with varying stages of cancer fulfilled diagnos tic criteria for psychiatric disorders. Of this $47 \%$, $68 \%$ had adjustment disorders with depressed or anxious mood, 13\% had major depression, and 8\% had organic mental disorders.

The reported prevalence of anxiety problems in cancer patient populations varies widely between studies, but in comparisons within the general population pathological anxiety is commoner in people with cancer than in those without any chronic medi cal condition ${ }^{7}$.

Many studies have indicated that cancer patients are facing serious psychological, physical and social problems. Consequently, most cancer patients experience difficulties in their ability to perform normal daily social activities, and a considerable fraction of these patients $(20 \%-46 \%)$ seem to suffer from moderate to severe emotional morbidity ${ }^{5}$.

In present study research it was observed that all the cancer patients have high level of anxiety and de pression at the diagnosis of cancer. Majority of patients said that they became very depressed and de veloped pessimistic attitude like death is much closed to him while some of the patients responded that on hearing this news they became depressed but decided to fight against the disease. In addition to that half of the patients replied that on hearing this news their family members encouraged him to fight against the disease and give full cooperation. The patients were worried about the fate of the disease. Most of the patients were apprehensive about future recurrence and 
progression of disease. Because of this fear some patients were in major depression and only few patients showed optimistic attitude towards this fear. Fifty percent of the patients were apprehensive and have some degree of depression so their daily activity is hampered. In present research it was reported that their abilities to do physical activities were reduced after the treatment of cancer. All the patients responded that their quality of life was affected once they diagnosed with this dreaded disease. This may be due to disease itself and its treatment. Most of the patients were irritable attitude towards others after disease diagnosis and during treatment phase, this may be due to some degree of anxiety and depres sion. In psychosomatic problems after the diagnosis of cancer the sleep duration of a person is usually af fected. To record these information half of the patients replied that their sleep was disturbed and decreased and night awakening was frequent because of anxiety and some disease related pain. This disturbance in sleep might be due their intrusive thoughts a bout the disease and treatment of the disease as there are several side effects of the breast cancer treatments. Pain is the troublesome complication of advanced cancer. More than half of patients experience the pain and discomfort. This was the main reason to affect the daily activities and they were not able to concentrate on their work and self daily activities. The apprehension in those patients who had surgical treatment modality has faced the psychological problem and some depression because of disfiguration of body part. This problem was mostly in breast and head/neck surgical cases. The side effects were the unbearable complication of cancer treatment. On treatment phase patient's group responded that at present discomfort due to chemotherapy was unbeara ble then cancer itself. This was also supported by another group in follow up phase because they already faced this problem previously and still have some de gree of sequel of side effects. All human beings prefer to live in social environment. But after the diagnosis of cancer some patients withdraw themselves from social activities and restrict themselves to within and also after diagnosis of cancer behavior of the people with the patient is changed and mostly people took sympathy for the patient. Almost all patients have financial problem while they were taking cancer treatment. This indirect factor may change the attitude and add some more anxiety to the patients. There may be so many reasons along with the expense of treatment; behavioral changes and depres sion further worsen the relationship with others.

The findings of present survey it has been observed that the patients involved in cancer undergo several physical and psychological effects. During the cancer treatment patients psychological treatment is must to boost the self esteem and courage of the patient to fight against the disease.

\section{CONCLUSION}

Treatment for these psychosomatic and psychological illnesses can help people with cancer feel more opti mistic and have a better quality of life. But there isn $\mathfrak{t}$ good evidence to support the idea that these inter ventions can reduce the risk of cancer, keep cancer from recurrence, or help the person with cancer live longer. Still, things like imagery, hypnosis, or relaxation can be used to help reduce the stress that of ten comes with a cancer diagnosis. People with cancer may feel blameworthy about their emotional re sponses to the disease. They may feel pressure to keep an optimistic attitude at all times, which is often impractical. This feeling of pressure can come from within themselves or from other people, or both. Sadness, depression, guilt, fear, and anxiety are all normal parts of learning to cope with major life changes, and a cancer diagnosis is a major life change. Trying to ignore these feelings or not talking with others about them can make the patient with cancer feel alone. It can also make the emotional pain worse. And, some people feel blameworthy themselves when they can $\mathrm{t}$ be optimistic which only adds to their psychological burden .

This research survey suggests that support from the treating physician; family members and society people play a very important role to encourage the pa- 
tients to fight against the disease. Such kind of awareness is of great significance for decreasing the morbidity rate and better quality of life of patients .

\section{REFERENCES}

1. J Kua. The prevalence psychological and psychiatric sequele of cancer in the elderly. Annals Academy of medicine $2005 ; 34,3$.

2. Gurevich M, Devins GM, Psych C et al. Response Syndromes and Cancer: Conceptual and Assessment Issues. Psychosomatics 2002 ; $43: 259-281$.

3. Derogatis LR, Morrow GR, Fetting J, et al. The prevalence of psychiatric disorders among cancer patients. JAMA 1983; 249:751 -
757.

4. Alter CL, Pelcovitz D, Axelrod A, et al. Identification of PTSD in cancer survivors. Psychosomatics 1996;37:137-143.

5. Irvine D, Brown B, Crooks D, et al. Psychosocial adjustment in women with breast cancer. Cancer 1991; 67 :1097-1117.

6. Herschbach P, Keller M, Knight L, et al. Psychological problems of cancer patients: a cancer distress screening with a cancer-specific questionnaire. British Journal of Cancer 2004; 91 :504 - 511.

7. Wells KB, Golding JM and Burnam MA. Psychiatric disorder in a sample of the general population with and without chronic medical conditions. Am J Psychiatry 1988; 145 : $976-981$. 